\title{
(⿹

\section{En mann i 70-årene med ryggmargsskade, feber og delirium}

NOE Å LAERE AV

\section{HILDE MARIE TORGAUTEN}

E-post: hilde.marie.torgauten@helse-bergen.no Nevrologisk avdeling

Haukeland universitetssjukehus

Hilde Marie Torgauten er lege i spesialisering ved Nevrologisk avdeling ved Haukeland universitetssjukehus.

Forfatteren har fylt ut ICMJE-skjemaet og oppgir ingen interessekonflikter.

\section{PETTER SCHANDL SANAKER}

Nevrologisk avdeling

Haukeland universitetssjukehus

Petter Schandl Sanaker er spesialist i nevrologi og overlege ved Haukeland universitetssjukehus. Forfatteren har fylt ut ICMJE-skjemaet og oppgir ingen interessekonflikter.

\section{TIINA REKAND}

Nevrologisk avdeling

Haukeland universitetssjukehus

Tiina Rekand er spesialist i nevrologi og overlege ved Haukeland universitetssjukehus og professor ved Göteborgs universitet.

Forfatteren har fylt ut ICMJE-skjemaet og oppgir ingen interessekonflikter.

En eldre mann pådro seg en cervikal ryggmargsskade etter et fall i trappen.

Rehabiliteringsprosessen ble forsinket av stadige infeksjoner med få kliniske funn.

Ryggmargsskade omfatter også skade på innervasjonen til indre organer, og gjør at akutt sykdom kan presentere seg annerledes enn normalt.

En mann i 70-årene med Bekhterevs sykdom, diabetes type 2 og koronarsykdom ble innlagt på kirurgisk avdeling ved lokalsykehuset etter et fall i en trapp. Ved innkomst til akuttmottak var han bevisst og orientert, men hadde ingen motorisk respons i over- eller underekstremiteter. Det var frie luftveier, regelmessig normofrekvent puls og blodtrykk på 8o/6o mm Hg. CT av hodet, nakken, thorax, abdomen og bekkenet etter traumeprotokoll viste en columnafraktur i nivå $\mathrm{C}_{4}-\mathrm{C}_{5}$. Etter $\mathrm{CT}$-undersøkelsen ble pasienten ukontaktbar. Blodgassmåling viste respiratorisk acidose, og det var mistanke om hypoventilasjon. Pasienten ble umiddelbart intubert. Supplerende CT caput med angiografi viste ingen tegn til traumatisk blødning, men derimot opphørt sirkulasjon i begge vertebralisarterier med retrograd fylning av bakre cerebrale kretsløp, forenlig med dislokasjon av vertebralisarteriene som følge av columnafraktur. Mannen ble overflyttet til nevrokirurgisk avdeling ved nærmeste regionsykehus og operert på vital indikasjon med reposisjon av cervikal fraktur og osteosyntese. MR av hjernen etter operasjon viste gjenopprettet 
sirkulasjon i vertebralisarteriene uten gjennomgåtte hjerneinfarkter. MR av ryggmargen viste ryggmargsødem i nivå $\mathrm{C}_{2}-\mathrm{C}_{5}$, forenlig med ryggmargsskade (figur 1 ).

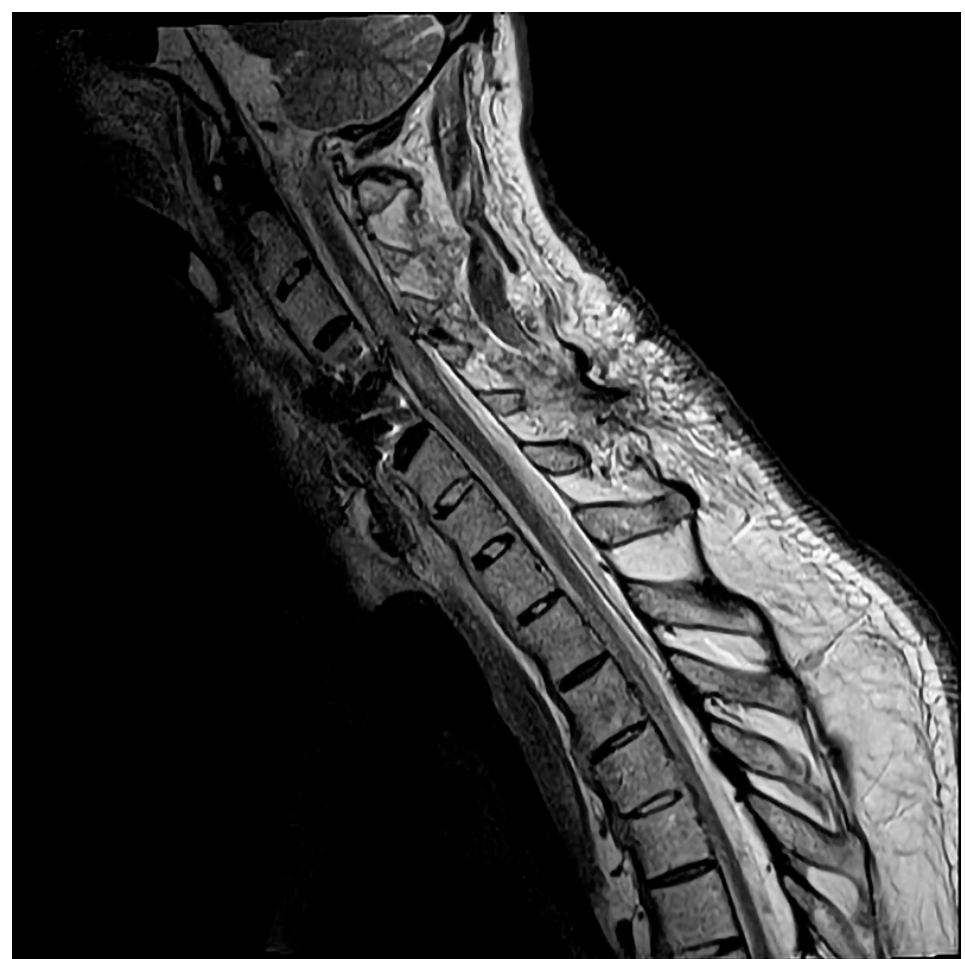

Figur $1 M R$ av cervikalcolumna viser status etter fikserende inngrep i bruddstedet $i C_{4}-C_{5}$-nivå. Bildet viser centromedullcer skade i $C_{3}-$ C6-nivå.

I Norge rammes 50-100 personer av traumatisk ryggmargsskade hvert år (1). Fall blant eldre ser ut til å gjøre at antall traumatiske ryggmargsskader øker (2). Høye (cervikale) ryggmargsskader kan være livstruende. Akutt respirasjonssvikt forekommer ved skade på innervasjonen til diafragma $\left(\mathrm{C}_{3}-\mathrm{C}_{5}\right)$ og interkostalmuskulaturen (Th1-Th11). Nevrogent sjokk med plutselig bortfall av sympatisk stimulering fra ryggmargens nivå Th1-L2 kan gi sirkulasjonssvikt som følge av vasodilatasjon og bradykardi. Hvis skaden omfatter hjertets sympatiske innervasjon, som utgår i nivå Th1-Th5, er det risiko for hjertestans og arytmier (3).

Ved oppvåkning fra narkose fremsto pasienten kognitivt adekvat. Han fikk trakeostomi, da man antok at det ville være behov for respirasjonsstøtte i lengre tid, og behandling med hostemaskin. Han var hypotensiv med behov for vasopressor (noradrenalininfusjon $0,13 \mathrm{mg} / \mathrm{kg} / \mathrm{min}$ ) for å opprettholde normalt middelarterietrykk (MAP). Pulsen var normofrekvent med nattlig bradykardi. Pasienten var medtatt og hadde behov for parenteral ernæring selv om svelgfunksjonen var normal. Han hadde urinretensjon, manglet sensibilitet for blærefylning og trengte permanent blærekateter. I løpet av 14 dager og etter langsom nedtrapping av noradrenalininfusjon stabiliserte middelarterietrykket seg over $60 \mathrm{~mm} \mathrm{Hg}$, men på grunn av vedvarende uttalt ortostatisme ble det lagt til fast blodtrykkshevende behandling (etilefrin $10 \mathrm{mg} \times 3$ peroralt). Mannen trengte intermitterende respirasjonsstøtte via trakeostomi. På dette tidspunktet ble det bemerket $\emptyset$ kende bukomfang, kvalme og oppkast, og derfor tatt CT abdomen på grunn av mistanke om paralytisk ileus. Bildet viste ingen tegn til ileus, men galleblæresten uten galleblærebetennelse, som ble vurdert som tilfeldig funn. Etter dette, to uker etter skaden, ble pasientens tilstand ansett som stabil, og han ble overflyttet til nevrologisk avdeling.

Den kliniske undersøkelsen med kartlegging av ryggmargsskaden ble gjort etter internasjonal mal (American Spinal Injury Association (ASIA) Impairment Scale) (4), og ryggmargsskaden ble karakterisert som inkomplett med kvadriplegi, men delvis intakt sensibilitet, og med nevrologisk skadenivå C2. Ved ryggmargsskade skades også det autonome nervesystemet. Vanlige sekveler er hypotensjon og ortostatisme, bradykardi, respirasjonssvikt, nedsatt tarmperistaltikk med obstipasjon, og urinveisdysfunksjon (5). 
Autonom dysfunksjon bør kartlegges under rehabilitering, gjerne med standardisert skjema. Spinalt sjokk gir forbigående arefleksi i timer til dager eller uker etter skaden, som gradvis erstattes av hyperrefleksi og spastisitet, som er forventet etter en sentralnervøs skade (5). Ryggmargsødem etter traume gjør at skadenivået kan fremstå høyere enn reelt i akuttfasen hos noen pasienter, og kartlegging med ASIA Impairment Scale bør gjentas i rehabiliteringsperioden.

Like etter overflytting til nevrologisk avdeling fikk mannen feber, nedsatt allmenntilstand og økte nevropatiske smerter. Ved klinisk undersøkelse var det normale funn over hjertet og lungene. Abdomen var fortsatt var utspilt og meteoristisk. Oksygenmetningen var spontant fallende fra 98-99\% til 87-92\% med uendret respirasjonsstøtte. CRP var $115 \mathrm{mg} / \mathrm{l}$ (referanseområde $<5 \mathrm{mg} / \mathrm{l})$, og leukocytter normale på 8,1 $10^{9} / \mathrm{l}\left(4,0-11,0 \cdot 10^{9} / \mathrm{l}\right)$. Urinstiks fra permanent urinkateter viste $2+$ for leukocytter og ble sendt til dyrkning. Det var ingen tegn til infiserte trykksår i huden, og operasjonssåret ble inspisert uten funn av infeksjonstegn. Med CRP-stigning til over $200 \mathrm{mg} / \mathrm{l}$ valgte man å starte behandling med bredspektret antibiotikum (piperacillin/tazobaktam $4 \mathrm{~g} / 0,5 \mathrm{~g} \times 3$ intravenøst) mot mistenkt aspirasjonspneumoni. Røntgen thorax bekreftet en pneumonisuspekt parenkymfortetning og væske inntil høyre diafragma. Behandling med antibiotika i 10 dager ga klinisk bedring og normalisert temperatur, oksygenmetning og CRP. Dyrkning av urin viste ingen oppvekst av mikrober.

Infeksjoner etter ryggmargsskade har tradisjonelt vært årsak til alvorlige komplikasjoner, og sepsis som følge av infeksjon i luftveier, urinveier eller trykksår bidrar fortsatt til økt mortalitet i kronisk fase etter ryggmargsskade (6). Nedsatt hostekraft gir få symptomer ved luftveisinfeksjon, mens sekretstagnasjon samtidig gir $\emptyset$ kt risiko. Pasienten er disponert for urinveisdysfunksjon med tømningsvansker, sannsynlig refluks til øvre urinveier og behov for urinveiskateter. Immobilisering og nedsatt sensibilitet gir risiko for trykksårutvikling.

Fire uker etter skaden fikk pasienten på ny feber og nedsatt allmenntilstand. Fysioterapeut bemerket tydelig $ø \mathrm{kt}$ spastisitet i alle ekstremiteter. Samme dag var det blitt innlagt midlertidig perkutan endoskopisk gastrostomi (PEG) som supplerende næringsinntak, da pasienten var medtatt. Funn etter klinisk undersøkelse av hjertet, lungene og abdomen var uendret fra tidligere, og huden omkring PEG-inngang var upåfallende. Orienterende blodprøver viste CRP $109 \mathrm{mg} / \mathrm{l}$ og leukocyttverdier innenfor referanseområdet. Man vurderte at CRP-stigningen muligens kunne skyldes kirurgi. Kontrollblodprøver etter et døgn viste imidlertid stigende CRP til $173 \mathrm{mg} / \mathrm{l}$, leukocytter $10,0 \cdot 10^{9} / \mathrm{l}$ og nøytrofile granulocytter $8,3 \cdot 10^{9} / 1\left(1,6-8,3 \cdot 10^{9} / 1\right)$. Røntgen thorax var normalt. Urinstiks fra kateter viste igjen lett utslag på leukocytter, og ble sendt til dyrkning. Man konfererte med infeksjonsmedisiner, som undersøkte pasienten og bemerket utspilt abdomen med mulig klingende tarmlyder og lett trykkømhet i øvre venstre kvadrant. I fravær av andre kliniske funn vurderte man abdominalt infeksjonsfokus som en mulighet - spesielt med tanke på nylig gjennomført kirurgisk inngrep - og herunder abscess, ileus eller tarmperforasjon. Det ble tatt CT abdomen, som ikke viste ileus eller annen patologi, men galleblæresten som før, uten tegn til galleblærebetennelse. Nye blodprøver viste stigende CRP til $215 \mathrm{mg} / \mathrm{l}$ og leukocytter $11,4 \cdot 10^{9} / 1$, og ellers nøytrofile granulocytter, ALAT, ASAT, GT og kreatinin i referanseområdet. Det var vanskelig å identifisere sikkert infeksjonsfokus, og man valgte å starte behandling med bredspektret antibiotikum (piperacillin/tazobaktam i samme dose som forrige infeksjon). Dette ga rask normalisering av temperatur og infeksjonsprøver. Behandlingen ble fortsatt i i alt 14 dager. Svar på dyrkningsprøver i etterkant viste ingen oppvekst av bakterier i blod eller urin fra permanent kateter. Det var oppvekst av gule stafylokokker i trakealsekret, som ble vurdert som uten klinisk betydning.

Pasienten rapporterte lett trykkømhet i abdomen. Det er etter vår erfaring vanskelig å predikere grad av bevart visceral sensibilitet $\mathrm{i}$ indre organer etter ryggmargsskade. Opptil $80 \%$ av ryggmargsskadde pasienter har obstipasjon og tømningsforstyrrelser som sekvele (7), noe som kan gjøre det vanskeligere å vurdere om abdominale symptomer er uttrykk for nyoppstått sykdom. Pasienten merket $ø$ kende spastisitet og nevropatiske smerter under 
infeksjon. Slike symptomer med spontan forverring av kjente sekveler er ikke uvanlig ved interkurrent sykdom.

To måneder etter skaden ble pasienten på ny febril. Ved undersøkelse var han ikke orientert for tid. Han var ikke nakkestiv. Respiratorisk og sirkulatorisk var han uendret. Blodprøver viste CRP $91 \mathrm{mg} / \mathrm{l}$, leukocytter $10,3 \cdot 10^{9} / \log$ nøytrofile granulocytter $7,5 \cdot 10^{9} /$ l. Urinstiks fra kateter viste utslag på leukocytter, nitritt og blod, og det ble startet peroral antibiotikabehandling mot antatt urinveisinfeksjon (trimetoprim-sulfametoksazol $160 \mathrm{mg} / 800 \mathrm{mg} \times 2$ ). Blodprøver neste dag viste raskt stigende CRP på 219-261 mg/l. Undersøkelse av hjertet, lungene og abdomen viste igjen normale funn, bortsett fra at abdomen var utspilt og diffust trykk $ø \mathrm{mt}$, men uten fokal trykkømhet, reflektorisk stramming eller bankeømhet over nyrelosjer. På mistanke om øvre urinveisinfeksjon ble det besluttet å bytte til intravenøs antibiotikabehandling (cefotaksim $2 \mathrm{~g} \times 3$ ). For å utelukke ny pneumoni ble det tatt røntgen thorax, som var normalt. Pasienten fremsto neste døgn $\varnothing$ kende delirisk med fallerende allmenntilstand. Vitale parametre var uendrete. Det var stigende CRP til $328 \mathrm{mg} / \mathrm{l}$ og forhøyete verdier av leukocytter på $13 \cdot 10^{9} / \mathrm{l}$ og nøytrofile granulocytter på 10,4 $\cdot 10^{9} /$ l. Verdiene av ALP, ASAT, GT og kreatinin var innenfor referanseområdet, mens bilirubin var lett forhøyet på $23 \mu \mathrm{mol} / \mathrm{l}(<19 \mu \mathrm{mol} / \mathrm{l})$. Mannen klaget over brennende smerter i alle ekstremiteter. Han hadde hatt tregere avføring enn vanlig, og det var synlig $ø$ kt bukomfang, men uendrete funn ved undersøkelse av abdomen. Etter diskusjon i kollegiet valgte man nå å be om et umiddelbart kirurgisk tilsyn på grunn av mistanke om akutt abdomen. Kirurgisk vakthavende fant lett trykkømhet ved dyp palpasjon under høyre kostalbue og utspilt abdomen, men ingen kliniske tegn til peritonitt. Dette var nokså sparsomme kliniske funn, men man valgte å henvise pasienten til CT abdomen på mistanke om abdominalt infeksjonsfokus, spesielt i galleveier. CTundersøkelsen viste galleblære med gallesten og fortykket vegg forenlig med galleblærebetennelse (figur 2). Det ble startet behandling av galleblærebetennelsen med piperacillin/tazobaktam intravenøst samt perkutan drenasje via galleblæredren, hvor det tømte seg gult puss. Behandlingen ga rask klinisk og laboratoriemessig bedring.

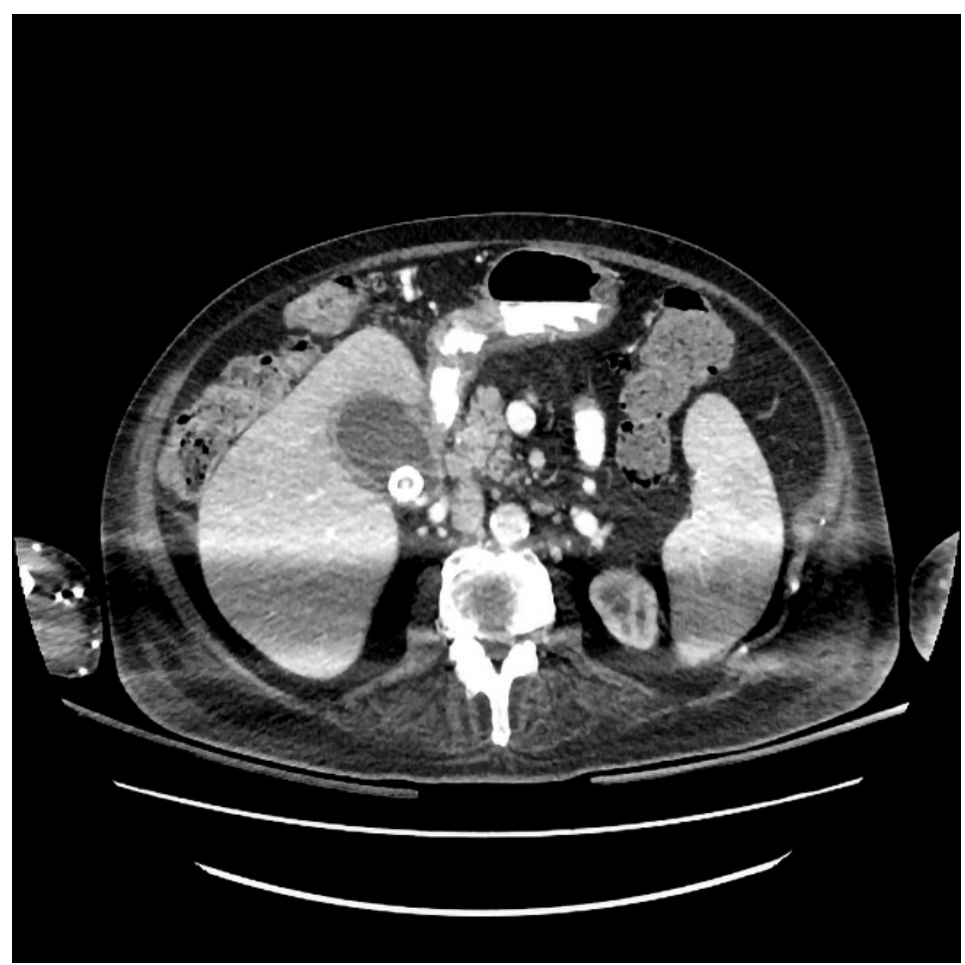

Figur 2 CT abdomen viser distendert galleblare med markert veggtykkelse, omkringliggende fokal fettvevsreaksjon samt konkrementer i gallebleren og gallegangen.

Ultralyd av abdomen ville vært en målrettet primærundersøkelse ved spørsmål om gallesten og galleblærebetennelse. Når CT abdomen ble valgt som primære undersøkelsesmetode, tyder det på et uklart klinisk inntrykk og et behov for å utelukke 
flere tilstander samtidig med rask bildediagnostikk.

Pasienten fikk to ganger residiv av galleblærebetennelse; begge ganger kort tid etter seponering av antibiotika og dren. Han hadde aldri spontane abdominale smerter. Det ble bemerket at han hadde klaget over smerter i høyre skulder under galleblærebetennelsene. Disse ble tolket som muskel-skjelettsmerter, nevropatiske smerter eller spastisitet, men i ettertid vurdert som mulig refererte smerter fra galleblæren.

På tross av risiko forbundet med operasjon i mannens tilstand ble det utført kolecystektomi etter tredje residiv. Operasjonen var vellykket. Pasienten var etter dette infeksjonsfri i lang tid og kunne for alvor starte planlagt rehabilitering. Ved utskrivelse til eget hjem noen måneder senere brukte han munnstyrt rullestol.

\section{Diskusjon}

Tilfellet illustrerer at diagnostikk av akutt sykdom hos en ryggmargsskadet pasient kan være utfordrende. Vår pasient hadde flere infeksjoner med sparsomme symptomer og kliniske funn. Da han fikk galleblærebetennelse, var symptomene ukarakteristiske, og de skilte seg lite fra tidligere infeksjoner.

Retrospektive studier viser at symptomene ved akutt abdomen hos ryggmargsskadde varierer fra klassiske (smerter i øvre høyre kvadrant) til atypiske (8-10). Eksempler på atypiske symptomer ved akutt abdomen er nedsatt allmenntilstand, diffus uvelhet, $ø \mathrm{kt}$ spastisitet og nevropatiske smerter (8-10). Refererte smerter, som rygg- og skuldersmerter ved galleblærebetennelse, er også beskrevet hos ryggmargsskadde (8). Autonom dysrefleksi er et fenomen ved høye ryggmargsskader som induseres av sansestimulering under skadenivået, og som gir en intens sympatisk aktivering med hypertensjon, intens hodepine, paradoksal svette og agitasjon (3). Den vanligste årsaken til autonom dysrefleksi er urinretensjon, men det er også rapportert som et tidlig symptom ved akutt abdomen (9). Det kan bemerkes at akalkuløs kolecystitt, en sjelden og alvorlig form for galleblærebetennelse uten gallesten som forekommer hyppigst hos intensivpasienter, er beskrevet i en kasuistikk med syv ryggmargsskadde pasienter, hvor ingen av dem hadde typiske symptomer (10).

Det ser ut til at prevalensen av gallesten er $\emptyset \mathrm{kt} \mathrm{hos} \mathrm{pasienter} \mathrm{med} \mathrm{ryggmargsskade.} \mathrm{Studier}$ viser en prevalens på 17-31\%, noe som er høyere enn blant funksjonsfriske (11,12). Aktuelle risikofaktorer for gallestensdannelse hos ryggmargsskadde i akuttfasen kan være langvarig parenteral ernæring, immobilisering og raskt vekttap ved muskelatrofi. Ryggmargsskadde har i kronisk fase $\emptyset \mathrm{kt}$ forekomst av diabetes (sannsynligvis grunnet muskelatrofi med $ø \mathrm{kt}$ andel kroppsfett (13)), som er en kjent risikofaktor for gallesten. I likhet med andre abdominale organer mottar galleblæren kompleks autonom innervasjon. Studier av galleblærens tømningsfunksjon etter ryggmargsskade med ultralyd og scintigrafi viser normal tømning (hovedsakelig parasympatisk styrt av n. vagus), mens relaksasjonsfasen (hovedsakelig styrt ved sympatisk signalering) ser ut til å være endret (14-16), og en kan tenke seg at endret lagringsfunksjon påvirker til økt gallestensdannelse. En nyere studie viste $\varnothing \mathrm{kt}$ forekomst av galleblærebetennelse etter ryggmargsskade uavhengig av tidligere påvist gallesten (17), noe som antyder at det kan være flere faktorer som bidrar til akutt galleblærebetennelse hos ryggmargsskadde, men dokumentasjonen er foreløpig sparsom. Vår pasient fikk påvist gallesten allerede to uker etter ryggmargsskaden som et tilfeldig funn, og hadde kjente risikofaktorer i form av høy alder og diabetes. Vi anser det som sannsynlig at vår pasient kan ha hatt gallesten forut for ryggmargsskaden. Med økt forekomst av gallestenssykdom i pasientgruppen og diagnostiske utfordringer ved akutt sykdom er hans sykehistorie i alle tilfelle noe å lære av.

Sykelighet og dødelighet har tradisjonelt vært høy etter ryggmargsskade, som følge av komplikasjoner. Leger i mange fagfelt møter den ryggmargsskadde pasient.

Vi mener at legen bør være årvåken og ha lav terskel for utvidet blodprøvetaking og bildediagnostikk dersom det er mistanke om alvorlig sykdom hos pasienten. Det er viktig å 
ta høyde for autonom dysfunksjon og redusert visceral sensibilitet. Når pasienten merker endringer fra habitualtilstanden, mener vi at det bør vektlegges.

\section{LITTERATUR:}

1. Norsk Ryggmargsskaderegister. Årsrapport for 2016 med plan for forbedringstiltak. Trondheim: St. Olav hospital, 2017.

https://stolav.no/Medisinskekvalitetsregistre/NorSCIR/NORSCIR-Arsrapport-2016.pdf(8.2.2019).

2. Hagen EM, Rekand T, Gilhus NE et al. Traumatiske ryggmargsskader - forekomst, skademekanismer og forløp. Tidsskr Nor Legeforen 2012; 132: 831-7. [PubMed][CrossRef]

3. Hagen EM, Rekand T, Grønning M et al. Kardiovaskulære følgetilstander etter ryggmargsskade. Tidsskr Nor Legeforen 2012; 132: 1115-20. [PubMed][CrossRef]

4. Krassioukov A, Biering-Sørensen F, Donovan W et al. International standards to document remaining autonomic function after spinal cord injury. J Spinal Cord Med 2012; 35: 201-10. [PubMed][CrossRef]

5. Kirshblum SC, Burns SP, Biering-Sørensen F et al. International standards for neurological classification of spinal cord injury (revised 2011). J Spinal Cord Med 2011;34: 535-46.

[PubMed][CrossRef]

6. Lidal IB, Snekkevik H, Aamodt G et al. Mortality after spinal cord injury in Norway. J Rehabil Med 2007; 39:145-51. [PubMed][CrossRef]

7. Sigurdsen E, Tørhaug T. Ryggmargsskade og tarmfunksjon. Tidsskr Nor Legeforen 2012; 132: 1107-10. [PubMed][CrossRef]

8. Bar-On Z, Ohry A. The acute abdomen in spinal cord injury individuals. Paraplegia 1995; 33: 704-6. [PubMed]

9. Miller BJ, Geraghty TJ, Wong CH et al. Outcome of the acute abdomen in patients with previous spinal cord injury. ANZ J Surg 2001; 71: 407-11. [PubMed][CrossRef]

10. Romero Ganuza FJ, La Banda G, Montalvo R et al. Acute acalculous cholecystitis in patients with acute traumatic spinal cord injury. Spinal Cord 1997; 35: 124-8. [PubMed][CrossRef]

11. Ebert E. Gastrointestinal involvement in spinal cord injury: a clinical perspective. J Gastrointestin Liver Dis 2012; 21: 75-82. [PubMed]

12. Moonka R, Stiens SA, Resnick WJ et al. The prevalence and natural history of gallstones in spinal cord injured patients. J Am Coll Surg 1999; 189: 274-81. [PubMed][CrossRef]

13. Kostovski E, Iversen PO, Hjeltnes N. Komplikasjoner etter kronisk ryggmargsskade. Tidsskr Nor Legeforen 2010; 130: 1242-5. [PubMed][CrossRef]

14. Tandon RK, Jain RK, Garg PK. Increased incidence of biliary sludge and normal gall bladder contractility in patients with high spinal cord injury. Gut 1997; 41: 682-7. [PubMed][CrossRef]

15. Nino-Murcia M, Burton D, Chang P et al. Gallbladder contractility in patients with spinal cord injuries: a sonographic investigation. AJR Am J Roentgenol 1990; 154: 521-4. [PubMed][CrossRef]

16. Fong YC, Hsu HC, Sun SS et al. Impaired gallbladder function in spinal cord injury on quantitative Tc-99m DISIDA cholescintigraphy. Abdom Imaging 2003; 28: 87-91. [PubMed][CrossRef]

17. Hsu CL, Wang MT, Ho YC et al. Increased risk of acute cholecystitis in patients with spinal cord injury: A nationwide population-based cohort study. Spine 2018; 43: 934-9. [PubMed][CrossRef]

Publisert: 6. mai 2019. Tidsskr Nor Legeforen. DOI: 10.4045/tidsskr.17.1104

Mottatt 18.12.2017, første revisjon innsendt 13.8.2018, godkjent 8.2.2019.

(C) Tidsskrift for Den norske legeforening 2020. Lastet ned fra tidsskriftet.no 